$$
\text { المجلة العراقية لعلوم الأرض- المجلدی- العدد - تشرين الثاني ^... }
$$

دراسة الخصائص النوعية والعناصر الأثرية لمياه نهر دجلة في مدينة الموصل

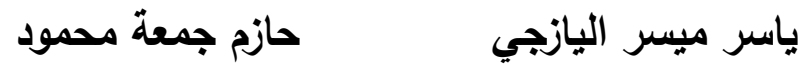

$$
\begin{aligned}
& \text { مركز بحوث السدود والموارد المائية } \\
& \text { جامعة الدوصل }
\end{aligned}
$$

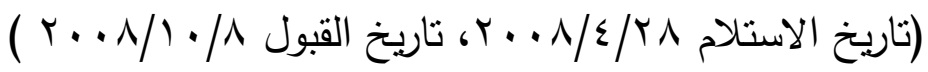

$$
\begin{aligned}
& \text { الملخص }
\end{aligned}
$$

تهنم الدراسة الحالية بتحديد خصائص ونوعية مياه نهر دجلة خلال مروره بمدينة الموصل. حيث تم

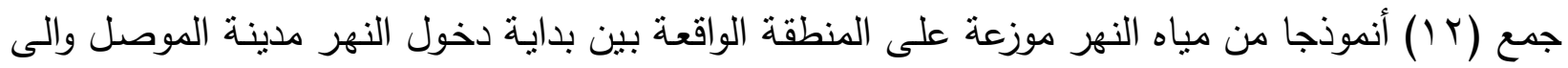

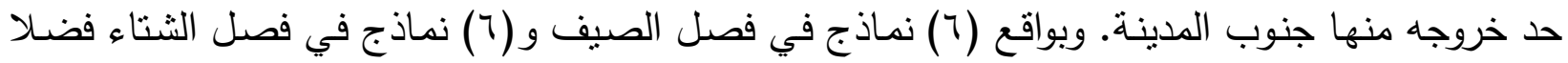

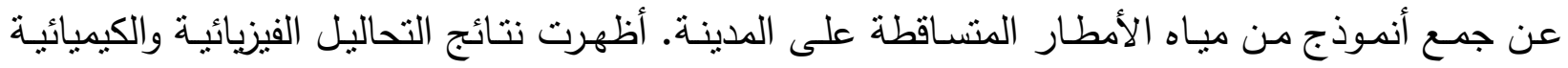

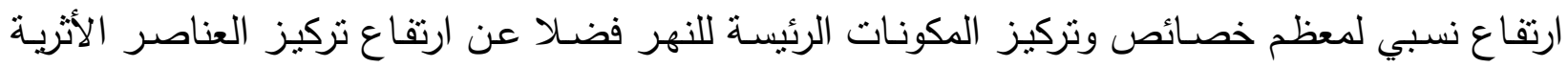

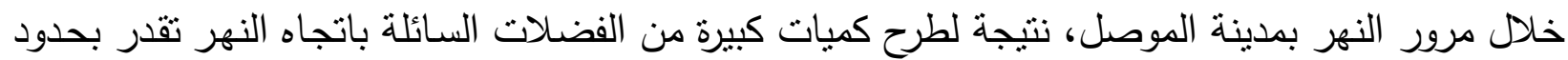

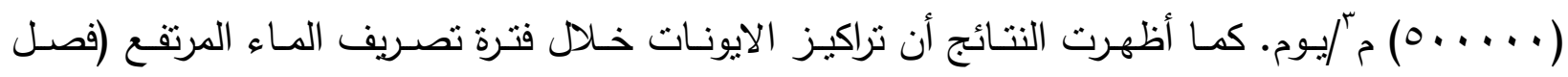

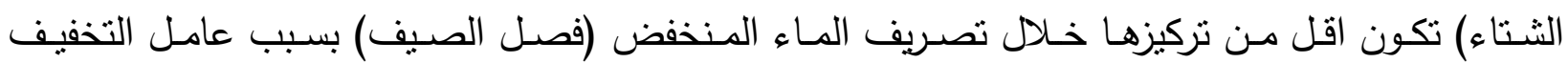
والانتتـار بمياه الأمطار ذات التزاكيز المنخفضة من الايونات وكذلك انخفاض عمليات التبخر خلال هذا

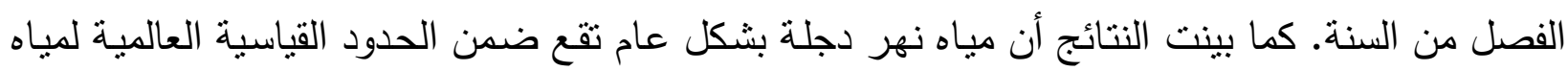
الثرب.

\title{
The Qualitative Characteristics and the Trace Elements for Tigris River Water in Mosul City
}

\author{
Yasir M. Al-yazichi Hazim J. Mahmood \\ Dams and Water Resources Research Center \\ Mosul University
}

\begin{abstract}
The present study is concerned with the characteristics and quality of Tigris water passing through in Mosul city. Twelve samples were collected from the river in the area between upstream and down stream of the city. Six samples in Summer and (6) samples in Winter, as well as, sample of the rain water falling on the city were collected. The
\end{abstract}




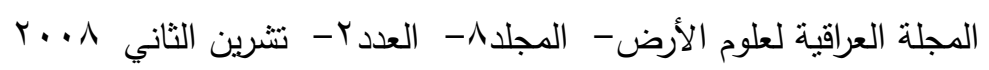

physical and chemical analyses showed relative increase in most of the concentrations of the principle components of the river, as well as high concentrations of the trace elements through downstream Mosul city, where a large quantities waste water is drained to (around $500000 \mathrm{~m} 3 /$ day) the river. The results also show that chemical major ions concentrations during rainy season is less from there than dry one this because of the lightening factor and the spreading of falling rain water with low concentrations of ions and also the slightness of the evaporation processing during this season. Results shows that Tigris water is generally are not within the world standard levels of drinking water.

\section{المقدمة}

يعد نهر دجلة أحد الموارد المائية العذبة المهمة في العراق. إذ تقع عليه مدينة الموصل كبرى مدن الثمال العراقي التي تتخذ دجلة المورد المائي الرئيسي في الاستخدامات اليومية، إذ تقدر كمية تصريف مياه نهر دجلة في مدينة الموصل حوالي (300) مّ/ثا (دائرة الري، ج . . ب). يتعرض النهر خلال مروره بالمدينة (منطقة الدراسة الحالية) إلى تصريف كميات كبيرة من الفضلات السكنية والصناعية السائلة عبر العديد من المصبات المنتشرة على ضفتي النهر، وتقدر كمية الفضلات المطروحة بـ (500000) مَّ/ يوم ( (and Jankeer, 2007 كمية المواد العالقة، وتغيرات في كمية الأوكسجين المذاب وزيادة في تراكيز العناصر الكيميائية. إذ تعتمد على نوعية وكمية الملوثات المطروحة ومنها المركبات العضوية والتي تأتي من الفعاليات المنزلية والمركبات اللاعضوية والمعدنية التي تأتي من الفعاليات الصناعية التي تشمل الحوامض والعناصر التقيلة والسامة مثل الرصاص والكروم وغيرها.

يقطع نهر دجلة عدد من التكاوبن والطبقات الجيولوجية ابتداً بدخول النهر الأراضي العراقية وحتى وعت التقائه بالزاب الأعلى جنوب الموصل، حيث يقطع في البداية تكوين المقدادية وباي حسن ثم تكوين انجانة وترسبات المصاطب النهرية والترسبات المتبقية ثم تكوين الفتحة إلى أن يصل النهر ناحية وانه، ثم يمر خلال الرواسب النهرية الحديثة وطبقات تكوين الفتحة إلى أن يصل مدينة الموصل (البياتي، .91 ( ) وكما

مبين في، الشكل (1) (1) (1)

تهدف الدراسة الحالية إلى قياس التغيير في الصفات الفيزيائية والكيميائية لمياه نهر دجلة عند مروره بمدينة الموصل لغرض معرفة مدى تأثنر مطروحات مدينة الموصل على نوعية وخصائص نهر 


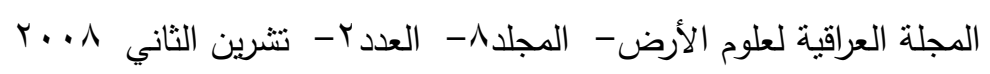

جمع وتحليل النماذج : شملت منطقة الدراسة نهر دجلة ابتداءا من دخوله مدينة الموصل في منطقة الرشيدية (شمالا) إلى منطقة

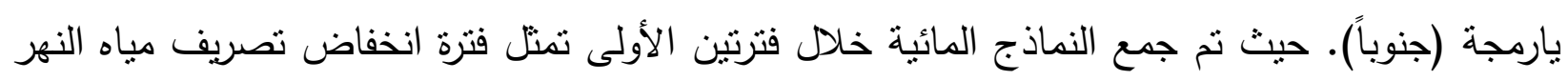

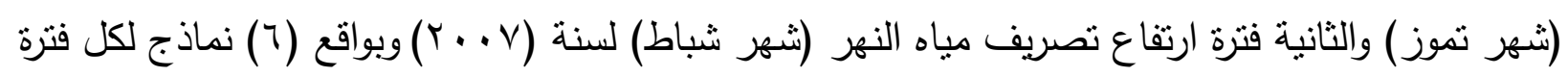

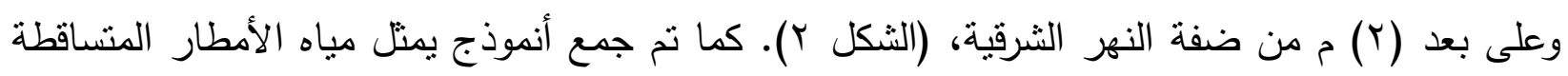
على مدينة الموصل في ( منطقة حي المثى) في بداية شهر الثاني (شباط). نم إجراء مجموعة من التحاليل الفيزيائية والكيميائية للنماذج وتتمل فياس الدالة الحامضية pH meter بجهاز نوع (HANNA 211) والايصالية الكهربائية (E.C) بجهاز نوع (HANNA 214) وقياس كمية الأملاح الذائبة الكلية (T.D.S).
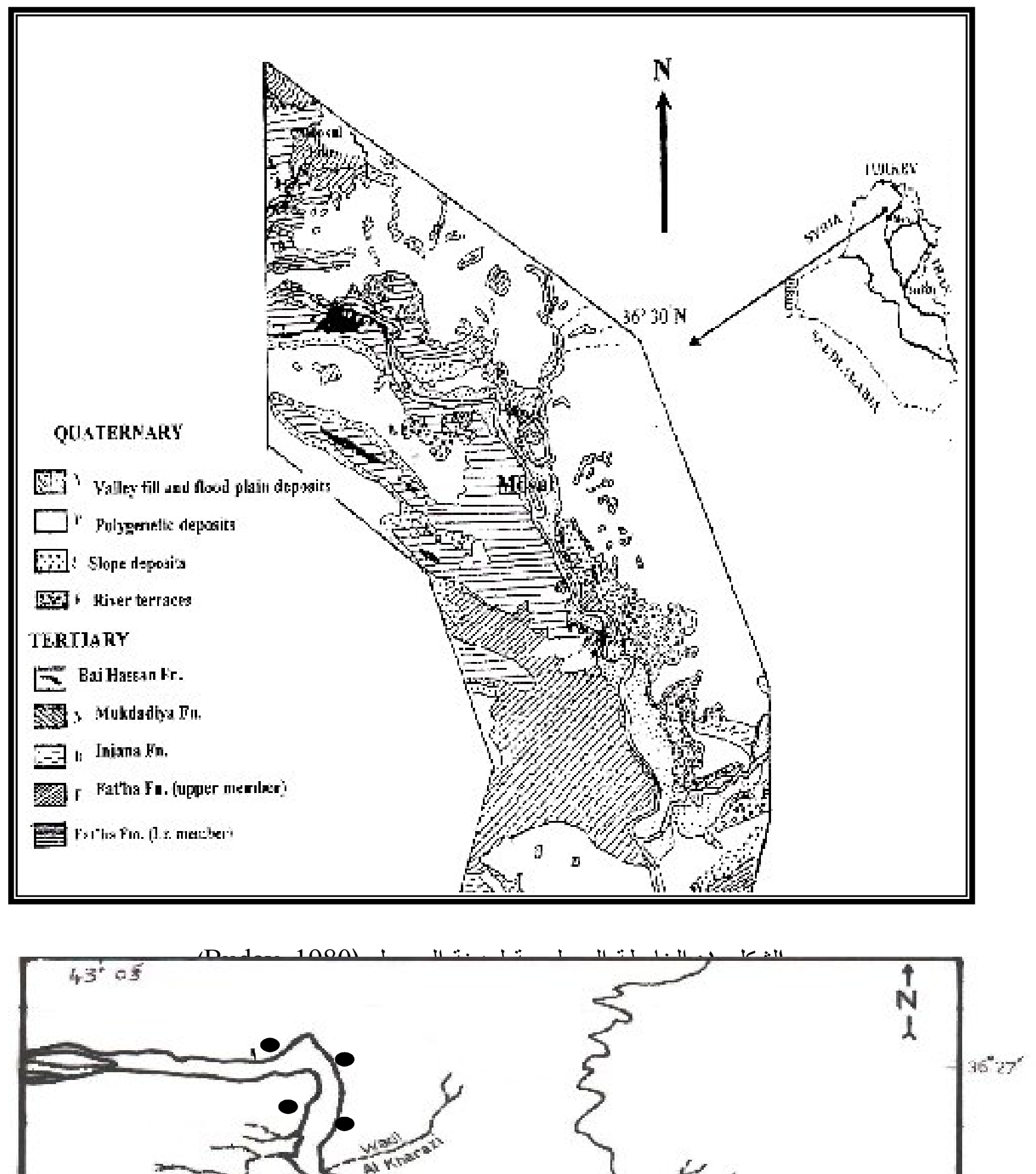


$$
\text { المجلة العراقية لعلوم الأرض- - المجلدی- العددץ- نتشرين الثاني ^... }
$$

أمـا عنصـر الكالسيوم والمغنيسيوم فقد تم حسـابهما بالطريقة التسـيح مـ(EDTA) وعنصـر الكلور بالتسحيح بنترات الفضة والبيكاربونات بالتسحيح مع حامض الكبريتيك المخفف. أمـا الكبريتات فقد تم حساب

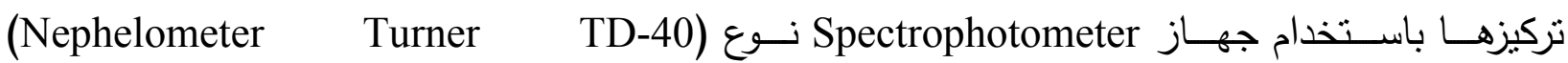
(عبـاوي وحسن، • 99 ( ) وتم إجراء هذه التحاليل في مختبر الجيوتكنيك / مركز بحوث السدود والموارد

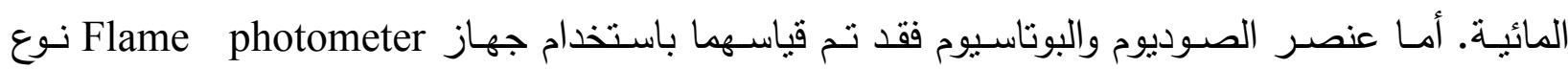
(Corning 400) $\cdot(\mathrm{ppm})$

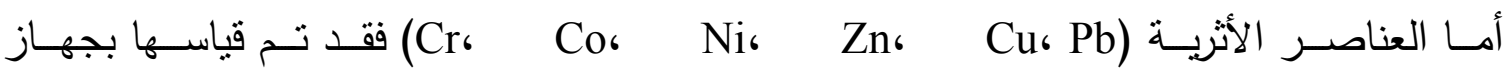

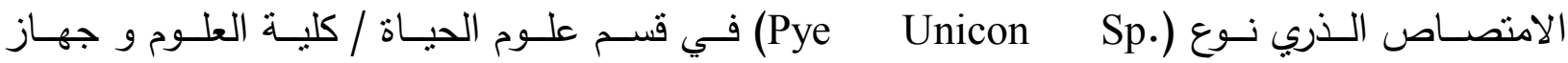
(Buck Scientific Model 210 VGA )

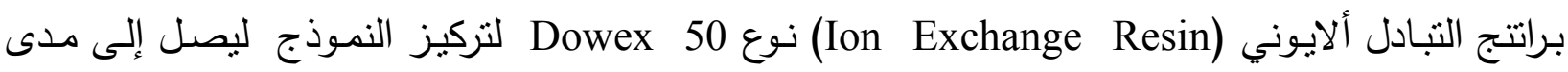
تحسس الجهاز، والنتائج معبر عنها بوحدة المايكرو غرام / لتر (ppb).

\section{النتائج والمناقشتة}




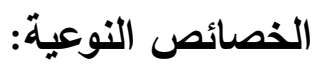

يوضح، الجدولين ( () و (r) نتائج القياسات الفيزيائية والتحاليل الكيميائية للايونات الرئيسة فضلا عن تحاليل العناصر الأثرية خلال فصل الصيف (تصريف الماء المنخفض) وفصل الثتاء ( تصريف الماء المرتفع ).

الدالة الحامضية الد بشكل عـام فـان اغلب المياه الطيبعيـة تميل نحو القاعديـة قليلا وذلك لوجود ايونـات الكربونـات والبيكاربونات (APHA, 1998).

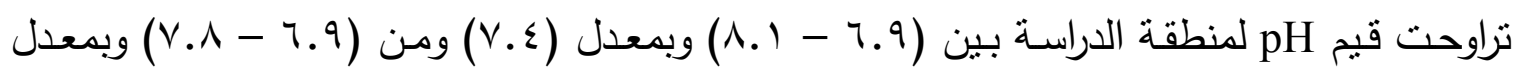

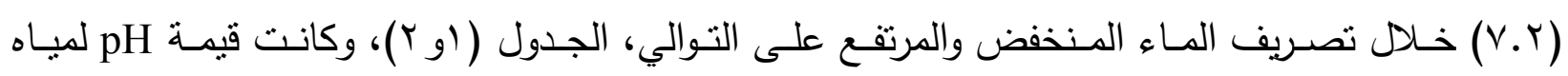
الأمطار (6.4) كما مبين في الجدول (r). وقيم pH هذه ضمن المدى الملائم لمعيشة الإنسان والكائنات

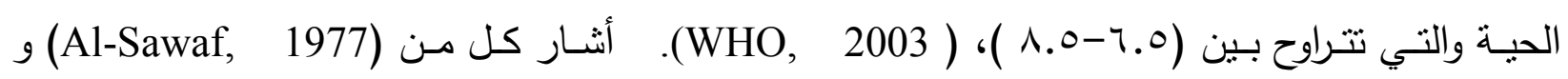
(Manahan, 2004)

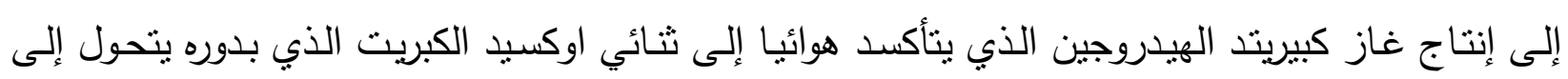
حامض الكبريتيك كما في المعادلات التالية :

Organic $-\mathrm{S} \stackrel{\text { Anaerobic bacteria }}{\longrightarrow} \mathrm{H}_{2} \mathrm{~S}$

$2 \mathrm{H}_{2} \mathrm{~S}+3 \mathrm{O}_{2} \longrightarrow 2 \mathrm{SO}_{2}+2 \mathrm{H}_{2} \mathrm{O}$

$\rightarrow \mathrm{H}_{2} \mathrm{SO}_{3} \quad \mathrm{SO}_{2}+\mathrm{H}_{2} \mathrm{O}$

$\mathrm{H}_{2} \mathrm{SO}_{3}+1 / 2 \mathrm{O}_{2} \longrightarrow \mathrm{H}_{2} \mathrm{SO}_{4}$

فضلا عن تكوين بعض المركبات الحامضية الأخرى التي تؤدي إلى انخفاض شديد لقيم الدالة الحامضية

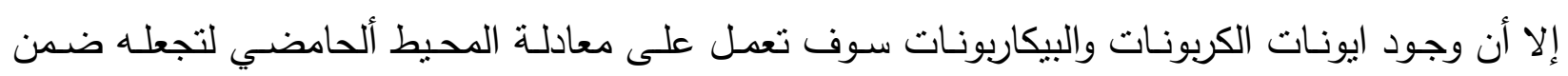
الحدود الطبيعية (7-9). (9-9)

\section{الايصالية الكهريائية Electrical Conductivity (E.C)}

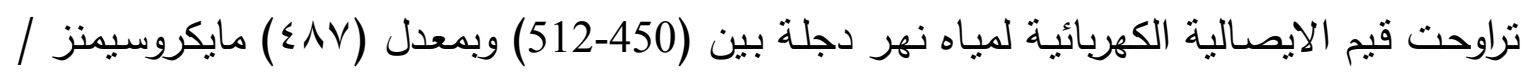

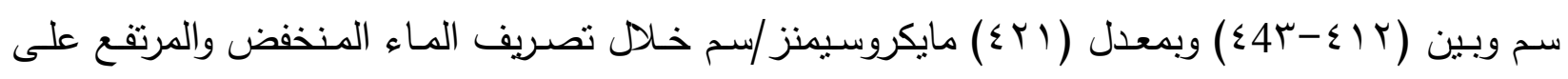

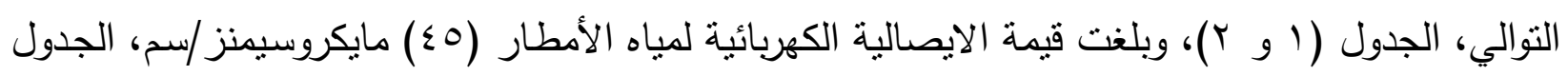

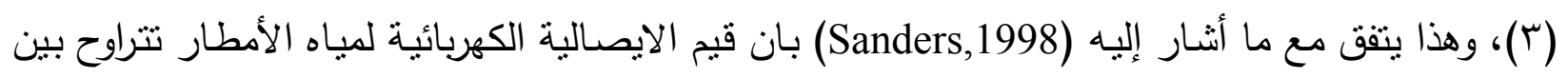

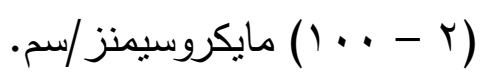


الجدول ا: تراكيز المكونات الرئيسة بوحدة الـ (ppm ) والعناصر الأثرية بوحدة الـ (ppb ) خلال التصريف المنخفض (شهر تموز).

\begin{tabular}{|c|c|c|c|c|c|c|c|}
\hline النماذج & 1 & r & $r$ & $\varepsilon$ & 0 & 7 & المعدل \\
\hline pH Unit. & 8.1 & 7.7 & 7.2 & 6.9 & 7.5 & 7.1 & 7.4 \\
\hline E.C $(\mu h o s / \mathrm{cm})$ & 450 & 472 & 486 & 510 & 492 & 512 & 487 \\
\hline T.D.S & 30. & $\varepsilon . r . \tau$ & $\leqslant Y \leqslant$ & r97.0 & $\varepsilon 1 \cdot .1$ & MVY.Y & raY.V \\
\hline TH & 204.4 & 228.8 & 247 & 245 & 243 & 234.5 & 233.7 \\
\hline $\mathrm{Ca}^{+2}$ & 55 & 60 & 64 & 66 & 61 & 62 & 61.0 \\
\hline $\mathrm{Mg}^{+2}$ & 16.3 & 19.2 & 21.2 & 19.5 & 22.2 & 19.4 & 19.6 \\
\hline $\mathrm{Na}^{+}$ & 12.7 & 15.2 & 17.3 & 18.2 & 16.5 & 16.6 & 16 \\
\hline $\mathbf{K}^{+}$ & 1.2 & 2.0 & 3.7 & 2.6 & 3.5 & 3.1 & 2.6 \\
\hline $\mathrm{HCO}_{3}$ & 170 & 193 & 177 & 182 & 175 & 166 & 177.0 \\
\hline $\mathrm{SO}_{4}^{-2}$ & 80 & 95 & 120 & 85 & 109 & 81 & 95 \\
\hline $\mathrm{Cl}^{-}$ & 15.7 & 19.2 & 20.8 & 23.2 & 22.9 & 24.1 & 20.9 \\
\hline $\mathbf{P b}^{+2}$ & 4.9 & 5.9 & 7.7 & 10.2 & 14.3 & 8.7 & 8.5 \\
\hline $\mathrm{Cu}^{+2}$ & 14 & 17 & 22 & 28 & 26 & 24 & 22 \\
\hline $\mathbf{Z n}^{+2}$ & 22.4 & 19 & 35.2 & 32 & 35.5 & 24.7 & 28.1 \\
\hline $\mathrm{Co}^{+2}$ & 2.4 & 2.2 & 6.8 & 4.6 & 5.8 & 5.2 & 4.5 \\
\hline $\mathrm{Ni}^{+2}$ & 12.9 & 15.4 & 17.9 & 18.8 & 10.2 & 17.2 & 15.4 \\
\hline $\mathrm{Cr}^{+3+6}$ & 17.9 & 13.4 & 9.8 & 22.6 & 19.1 & 15.3 & 16.3 \\
\hline
\end{tabular}

\section{المواد الصلبة الذائبة الكلية Total Dissolved Solids (T.D.S)}

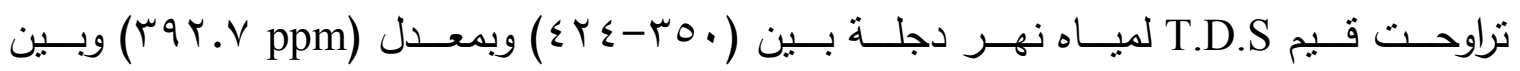

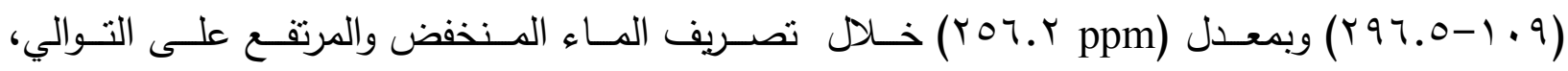

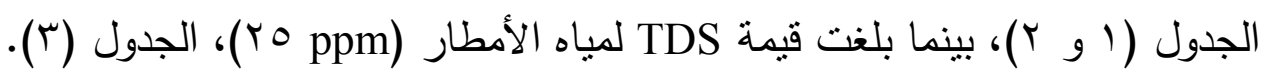

الجدول r: تراكيز المكونات الرئيسة بوحدة الـ (ppm ) والعناصر الأثرية بوحدة الـ (ppb ) خلا التصريف المرتفع (ثهر شباط). 


\begin{tabular}{|c|c|c|c|c|c|c|c|}
\hline النماذج & 1 & r & $r$ & $\varepsilon$ & 0 & 7 & المعدل \\
\hline pH Unit . & 7.8 & 6.9 & 7.1 & 6.9 & 7.2 & 7.3 & 7.2 \\
\hline E.C $(\mu h o s / \mathrm{cm})$ & 412 & 425 & 443 & 434 & 420 & 413 & 421 \\
\hline T.D.S & 257.9 & 109 & 285.2 & 294.4 & 294.4 & 296.5 & 256.2 \\
\hline TH & 176.6 & 191.7 & 195.7 & 192.8 & 179.8 & 188.6 & 187.5 \\
\hline $\mathrm{Ca}^{+2}$ & 49 & 57 & 55 & 52 & 51 & 50 & 53 \\
\hline $\mathrm{Mg}^{+2}$ & 13.2 & 12.0 & 14.2 & 15.3 & 12.7 & 15.5 & 13.8 \\
\hline $\mathrm{Na}^{+}$ & 6.1 & 7.2 & 6.9 & 8.4 & 7.1 & 7.5 & 7.2 \\
\hline $\mathbf{K}^{+}$ & 1.5 & 1.1 & 1.3 & 1.0 & 1.6 & 1.9 & 1.4 \\
\hline $\mathrm{HCO}_{3}^{-}$ & 97 & 109 & 115 & 122 & 129 & 108 & 113 \\
\hline $\mathrm{SO}_{4}^{-2}$ & 77.0 & 78.0 & 74.6 & 80.2 & 76.4 & 72 & 76.3 \\
\hline $\mathrm{Cl}^{-}$ & 14.1 & 20.9 & 18.2 & 15.5 & 16.6 & 14.6 & 16.6 \\
\hline $\mathbf{P b}^{+2}$ & 2.2 & 2.5 & 2.6 & 2.1 & 4.9 & 3.5 & 2.9 \\
\hline $\mathrm{Cu}^{+2}$ & 9.0 & 7.0 & 11.0 & 12.0 & 11.0 & 10.0 & 10.0 \\
\hline $\mathrm{Zn}^{+2}$ & 12.7 & 17.2 & 15.6 & 20.1 & 18.0 & 16.5 & 16.6 \\
\hline $\mathrm{Co}^{+2}$ & 1.6 & 2.1 & 2.4 & 5.0 & 6.3 & 5.6 & 4.3 \\
\hline $\mathrm{Ni}^{+2}$ & 8.6 & 9.5 & 10.2 & 8.3 & 11.6 & 9.2 & 9.5 \\
\hline $\mathrm{Cr}^{+3,+6}$ & 7. & 8.17 & 5.2 & 6.1 & 4.0 & 7.2 & 6.2 \\
\hline
\end{tabular}

\section{العسرة الكلية (Total Hardness}

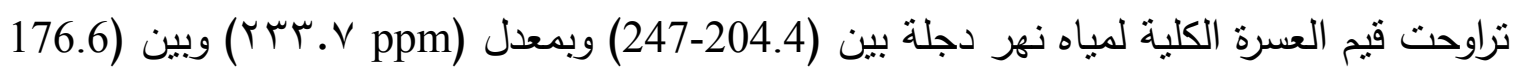

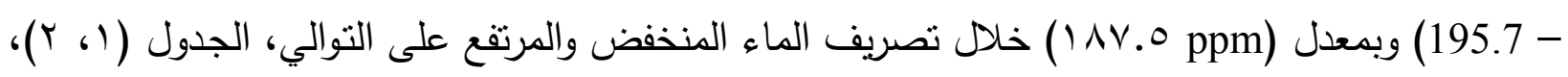

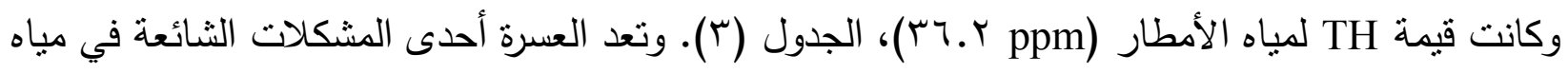

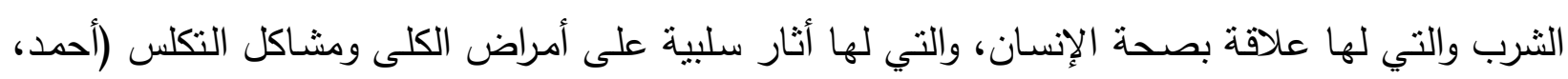
.$(r \cdot V$ وحسب تصـنيف (Todd and Mays, 2005) تعـد ميـاه نهـر دجلـة ضـمن الميـاه العسـرة

$$
\text { لأنها تقع ضمن مدى (10 - (10 - (1). }
$$




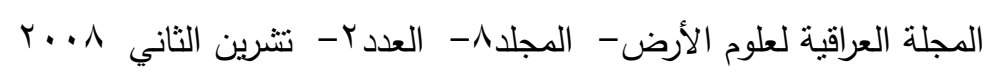

الجدول r : يمثل معدل تراكيز المكونـات الرئيسة للفضـات السائلة ومعدل تراكيز المكونات الرئيسة في ميـاه نهر دجلـة ومعدل تراكيز المكونـات الرئيسـة لميـاه الأمطـار والنتائج معبـر عنهـا بوحدة

\begin{tabular}{|c|c|c|c|c|c|c|c|c|c|c|c|}
\hline |الصفات المياه & pH & $\begin{array}{c}\text { E.C } \\
\boldsymbol{\mu h o s} / \\
\text { cm }\end{array}$ & T.D.S & TH & $\mathrm{Ca}^{+2}$ & $\mathrm{Mg}^{+2}$ & $\mathbf{N a}^{+}$ & $\mathbf{K}^{+}$ & $\mathrm{Cl}^{-}$ & $\mathrm{HCO}_{3}^{-}$ & $\mathrm{SO}_{4}^{-2}$ \\
\hline السضائلة" & 7.4 & 1600 & 655 & 352 & - & - & - & - & 70.5 & - & 254.4 \\
\hline ديلة "*هر & 7.3 & 445.5 & TYE. & 210.7 & 56.8 & 16.7 & 11.6 & 2.0 & 18.7 & 145.2 & 85.6 \\
\hline | الأمطار ". & 6.4 & 45 & ro & 36.2 & 14 & 0.32 & 1.6 & 0.35 & 0.7 & 2.1 & 6.4 \\
\hline & & & & & & & & & $\begin{array}{r}\cdot(1 \\
(r \cdots v\end{array}$ & 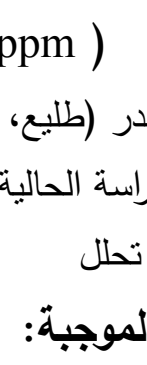 & 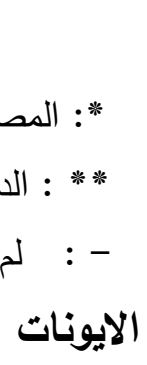 \\
\hline
\end{tabular}

يعد هذان الايونان شائعان في مياه الأنهار، ومصدرهما تجوية الحجر الجيري والجبسوم المتواجدة

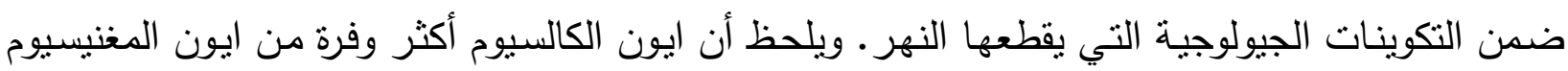

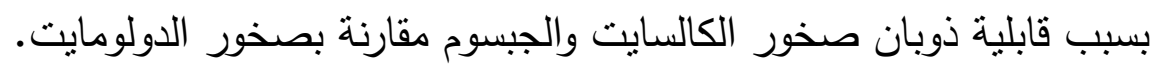

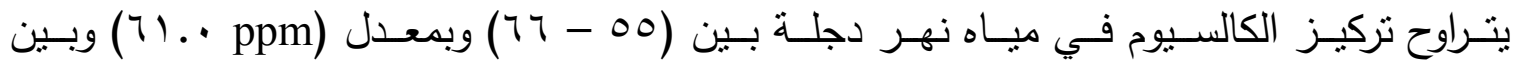

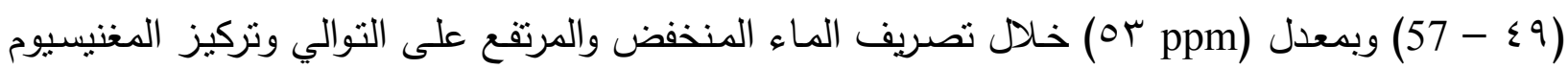

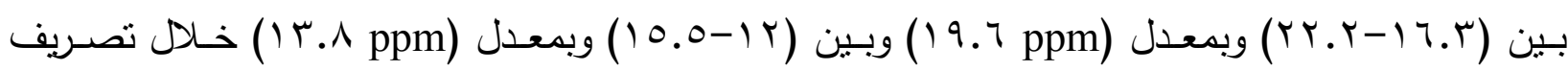

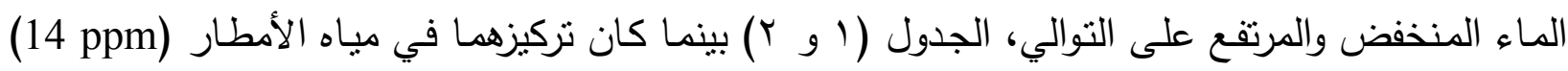
و (0.32 ppm) على النوالي، الجدول (r).

الصوديوم والبوتاسيوم (

يوجد ايون الصوديوم في المياه الطبيعية بنسبة اكبر من تركيز ايون البوتاسيوم ومصدره المعـادن

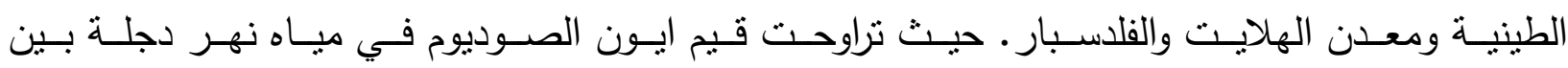

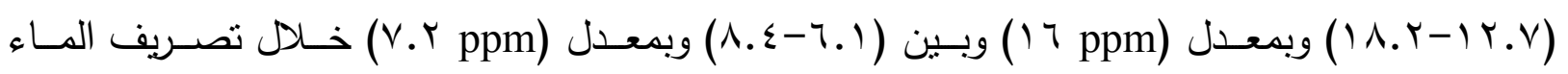




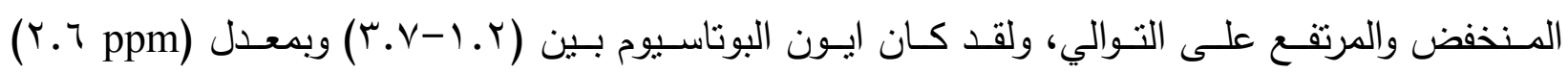

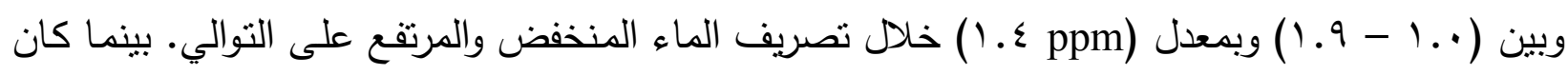

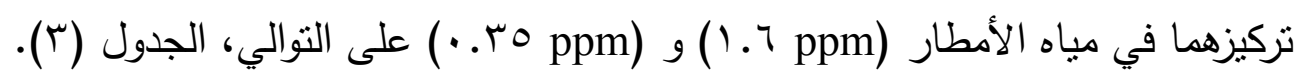

تعد ايونات البيكاربونات أحدى المكونات الرئيسية للمياه الطبيعية، وتتـتق البيكاربونـات من تجويـة صخور الحجر الجيري المنتشرة والني يقطعها النهر أثناء مسيره. ويتراوح تركيز ويتراوح تركيز

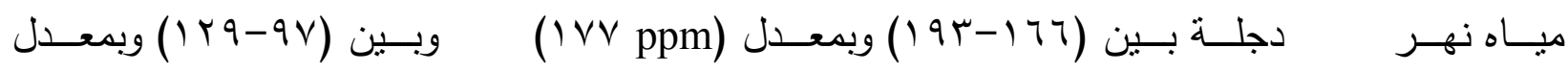
(l r ppm)

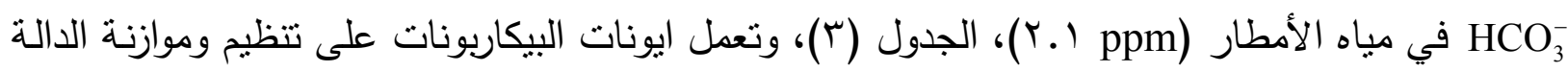

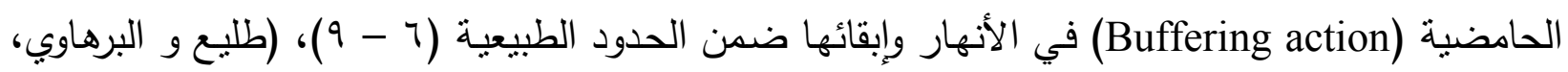
.$(r . .$.

$$
\text { الكبريتات ( SO }
$$

توجد الكبريتات في جميع أنـواع الميـاه الطبيعيـة ويتحرر جذر SO SOتيجـة للتجويـة الكيميائيـة

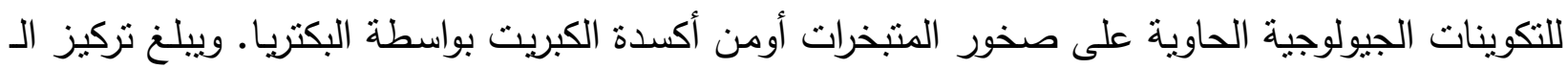

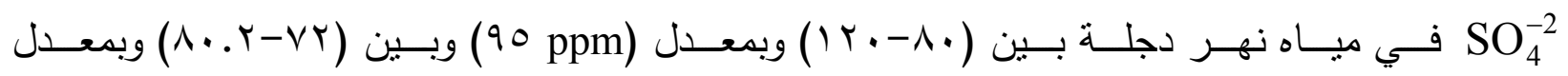

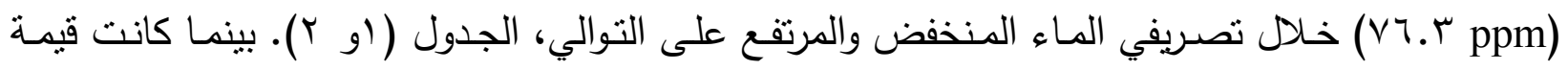

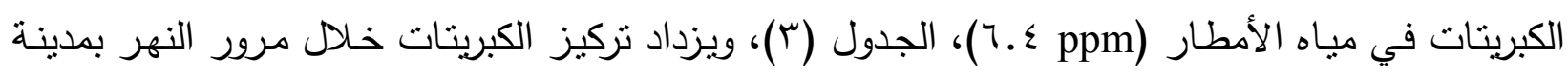

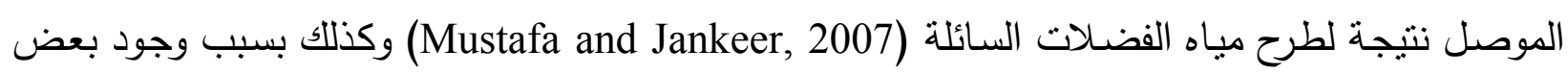

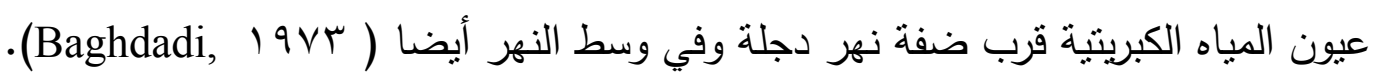

$$
\text { الكلوريد ( }
$$

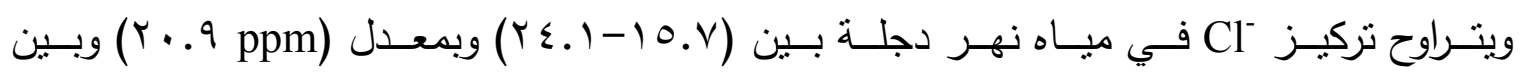

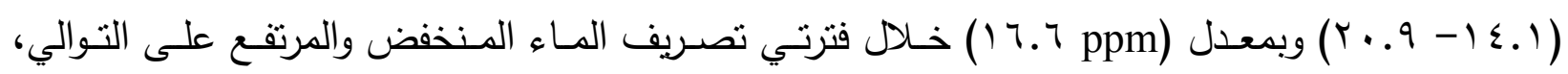

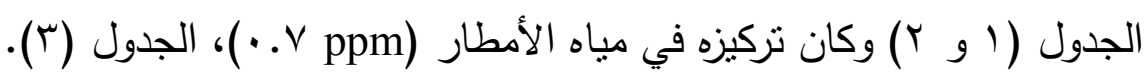




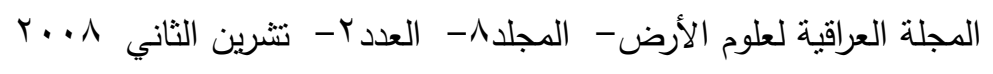

Trace Elements العناصر الأثرية

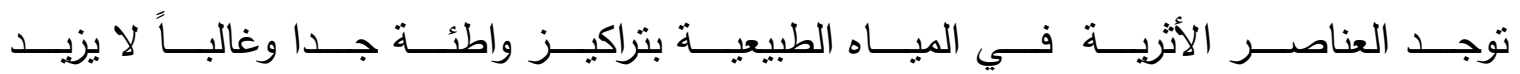

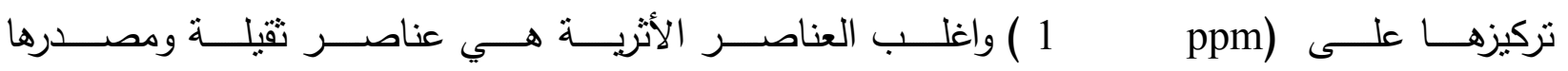

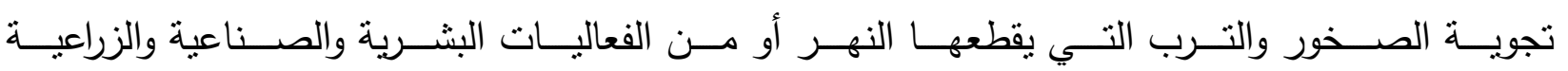
(Drever, 1997) وتتأثز تراكيزهـا ومعاملات أغنائها بعدة عوامل منها الدالة الحامضية وجهد الأكسدة والاختزال ودرجة الانتقالية وكذللك مدى امتزازها على اسطح المعادن الطينية. ورغم انخفاض وجودها ونها في

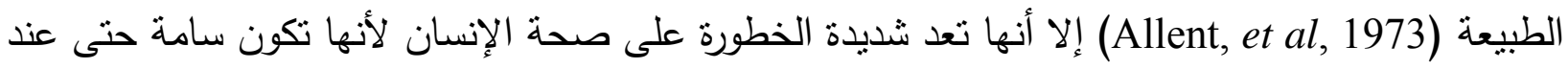

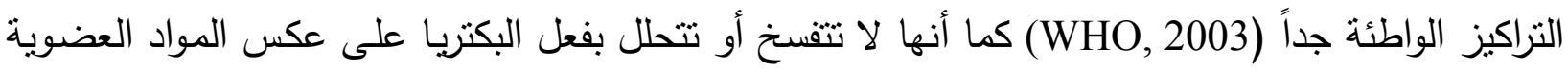

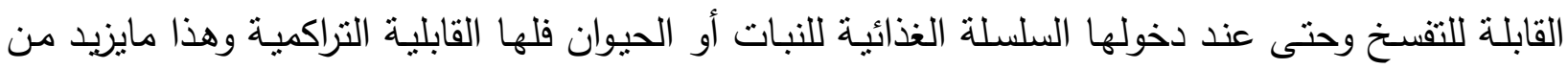

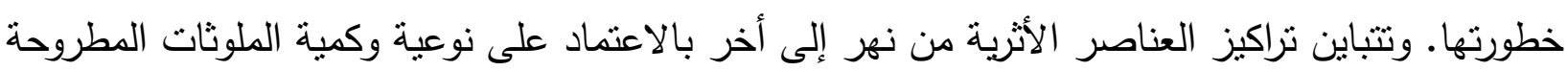

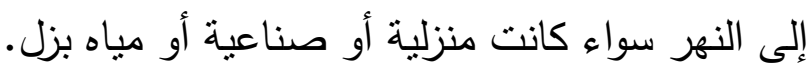

\section{: Lead $\left(\mathbf{P b}^{+2}\right)$ الرصاص}

يوجد الرصـاص في المياه الطبيعيـة بتركيز لا يتجاوز (WHO, 2003) (10 ppb) ومصـادره الطبيعية من المعادن الحاوية على عنصر الرصاص مثل (pbS) Galena ومعدن (PbC) Cerussite ومعدن (^.0 ppb)

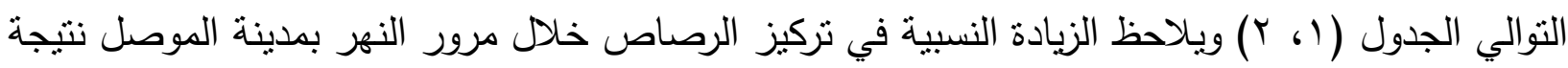

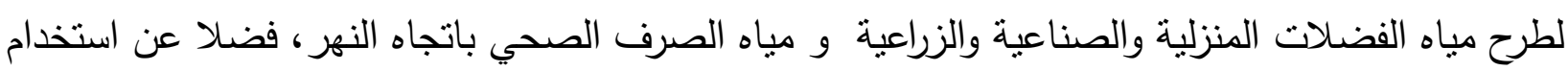

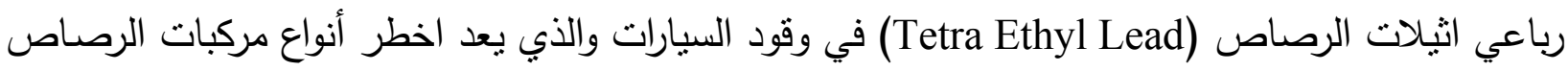
(Morris, et al., 1992)

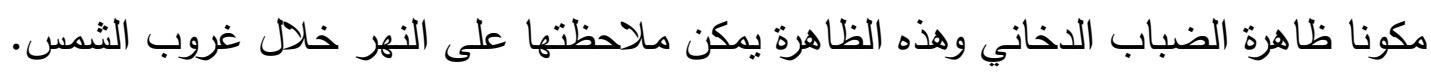

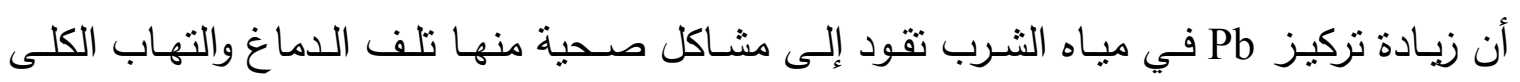

.(UNISCO, 1983)

\section{: Copper $\left(\mathrm{Cu}^{+r}\right)$ النحاس}

يبلغ تركيز النحاس في مياه الأنهار العذبة (WHO, 2003) (21 ppb) والحد المسموح به في مياه

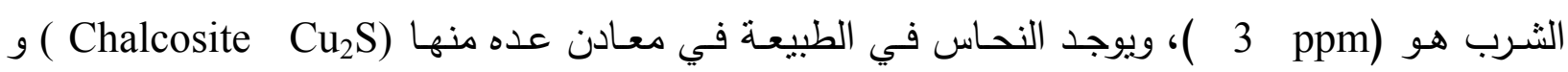




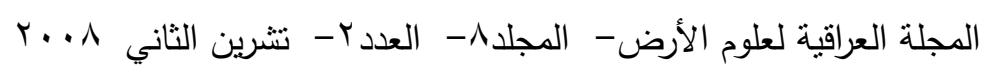

والمعادن السلكاتية مثل Chrysocolla (CuFeS $)$ Chalcopyrite اسطح المعادن الطينية والمواد العضوية.

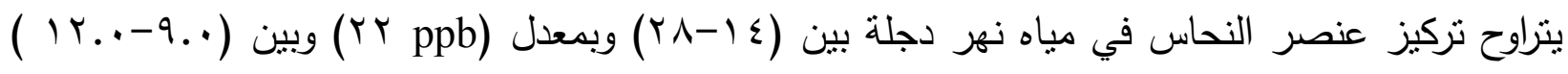

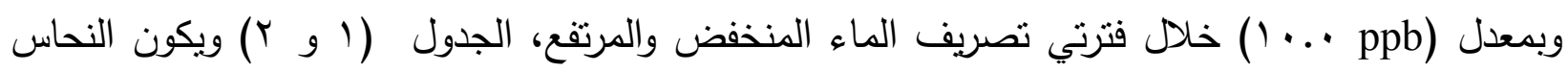
أكثر سمية في المياه العسرة والواطئة القلوية (Fetter, 1980) ويسبب امراضا كثيرة منها التقيوء والإسهال وأمراض القلب.

\section{: Zinc $\left(\mathbf{Z n}^{+r}\right)$ الخارصين}

يبلغ تركيز الخارصين في مياه الأنهار (r.ppb) (renoit and Rozon, 1998) ويوجد في الطبيعة في عدة معادن منها

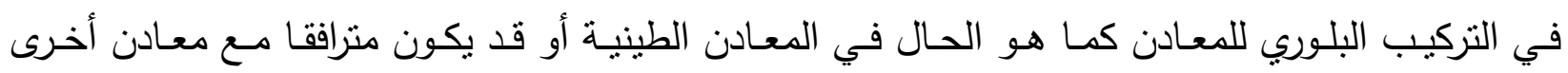

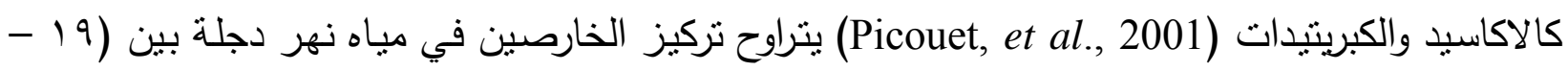

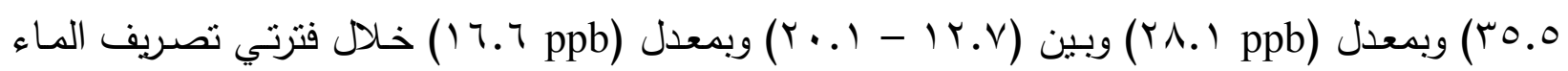

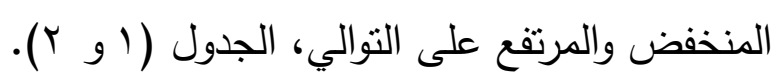

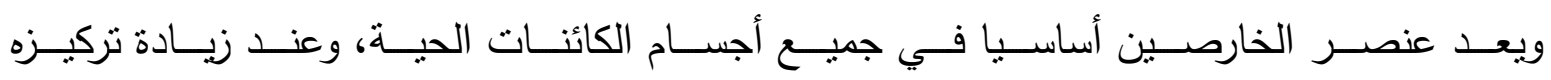

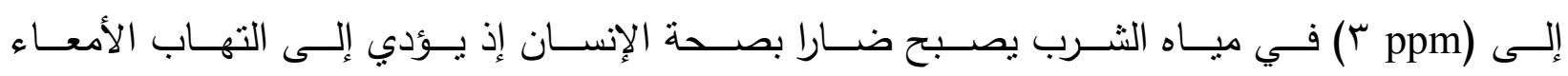
.(WHO, 2003)

\section{: Cobalt $\left(\mathrm{Co}^{+r}\right)$ الكويلت}

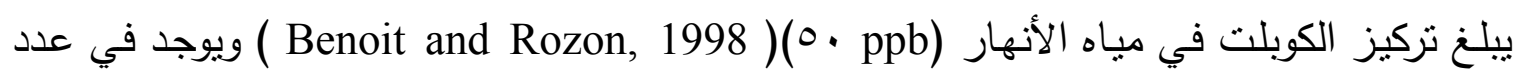

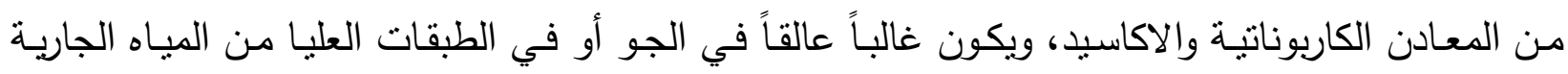
يتزاوح نركيز الكوبلت في نهر دجلة بين (r. (Yilmaz et al., 2003)

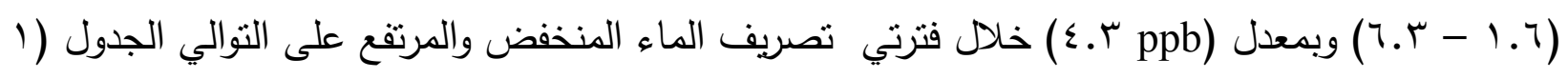

\section{: Nickel $\left(\mathrm{Ni}^{+r}\right)$ النيكل}

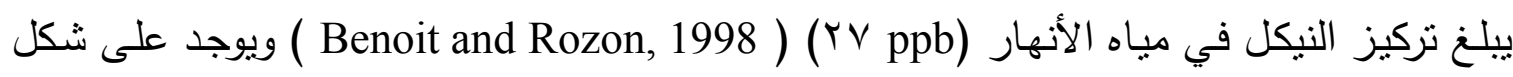
اكاسيد وكاربونات وسليكات مع الحديد (Morris, et al., 1992) وكذلك يمتز على المعادن الطينية واكاسيد وهيدروكسيدات الحديد، ويسبب زيادة تركيز النيكل عن (Y.ppm) مشاكل صحية للإنسان مثل السرطان 


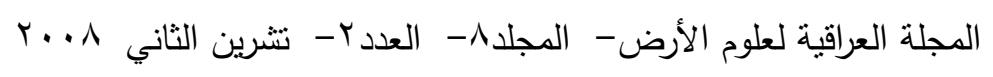

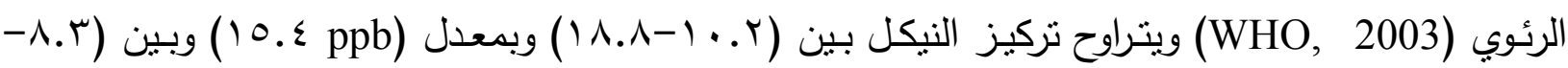

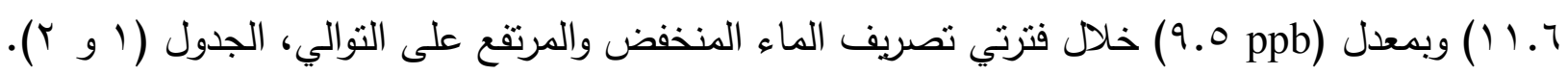
: Chromium $\left(\mathrm{Cr}^{+\uparrow, r}\right)$ الكرول

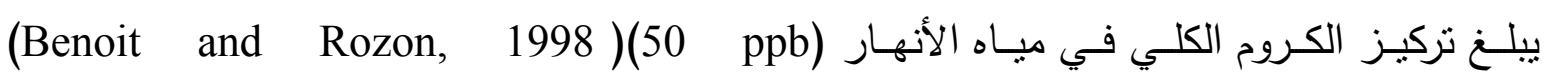
ويوجد في عدد من المعادن مثل الباروكسين والامفيبول وكذللك المعادن الطينية ويتواجد Cr في حالتي تأكسد

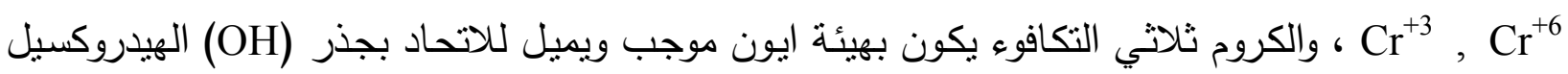
ليكون هيدروكسيد الكروم

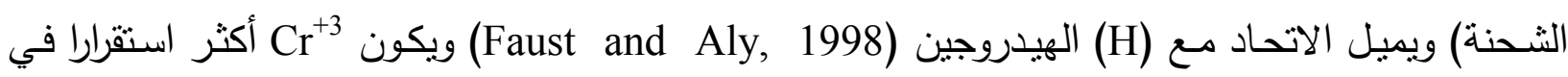

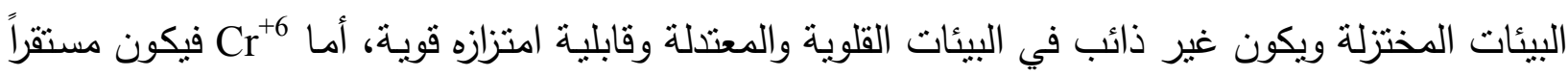

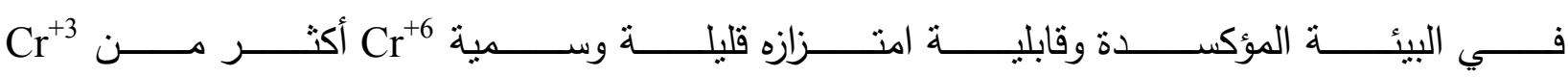

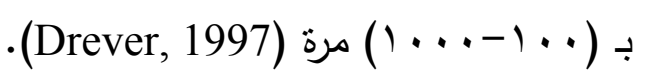

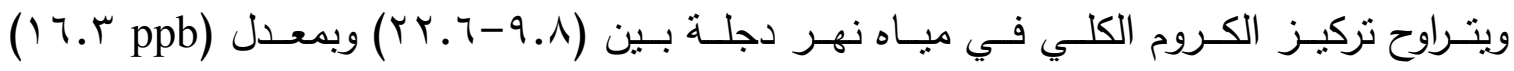

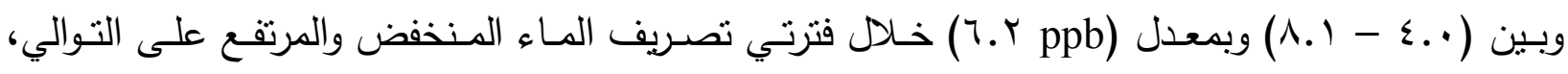

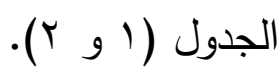

\section{مناقشة تغاير هيدروكيميائية نهر دجلة}

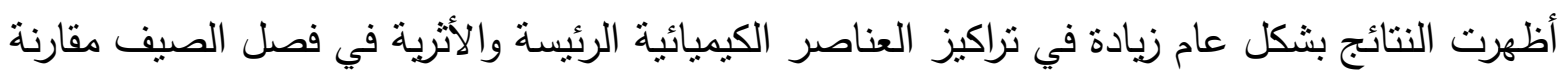

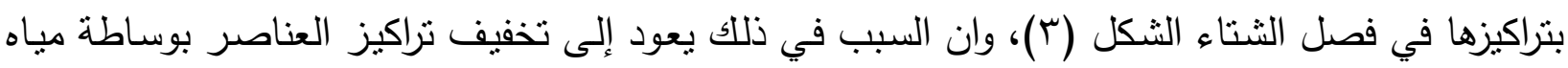

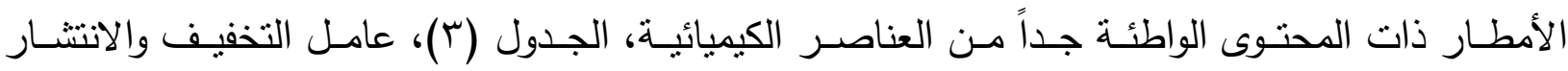
وكما يبين الثكل(؟) أن هنالك زيادة في نراكيز المكونات الكيميائية في (Dilution and Dispersion) النموذج رقم (ع) بسب قرب موقع النموذج من مصب مياه نهر الخوصر والذي يبعد عنه حوالي ( (0) )م. كما أن عمليات التبخر العالية في فصل الصيف نساعد على زيادة تراكيز الايونات الكيميائية في مياه نهر دجلة.

كما بينت نتائج التحاليل الكيميائية أن هناك ارتفاع نسبي في نراكيز العناصر الكيميائية في مياه نهر

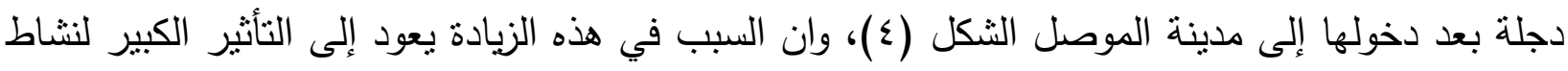

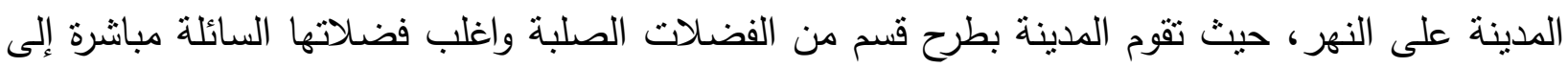
النهر دون أي معالجة. 


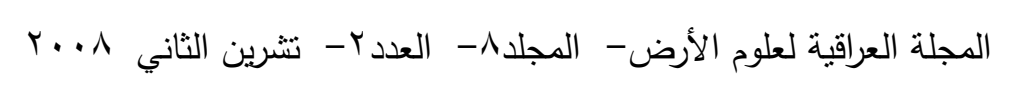

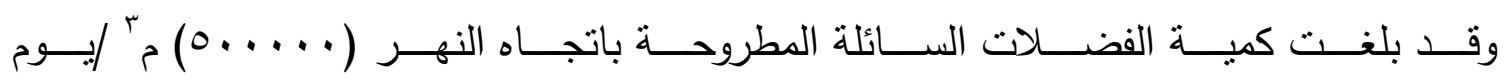

وتمتاز بارتفاع نسب الملوثات فيها وارتفاع تراكيز العناصر الكيميائية

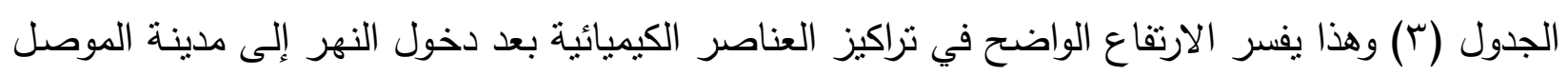
ألا أن مياه نهر دجلة لا تزال ضمن الحدود الطبيعية لمياه الثرب وفق الموصفات العاتيز العالمية الجدول(4).
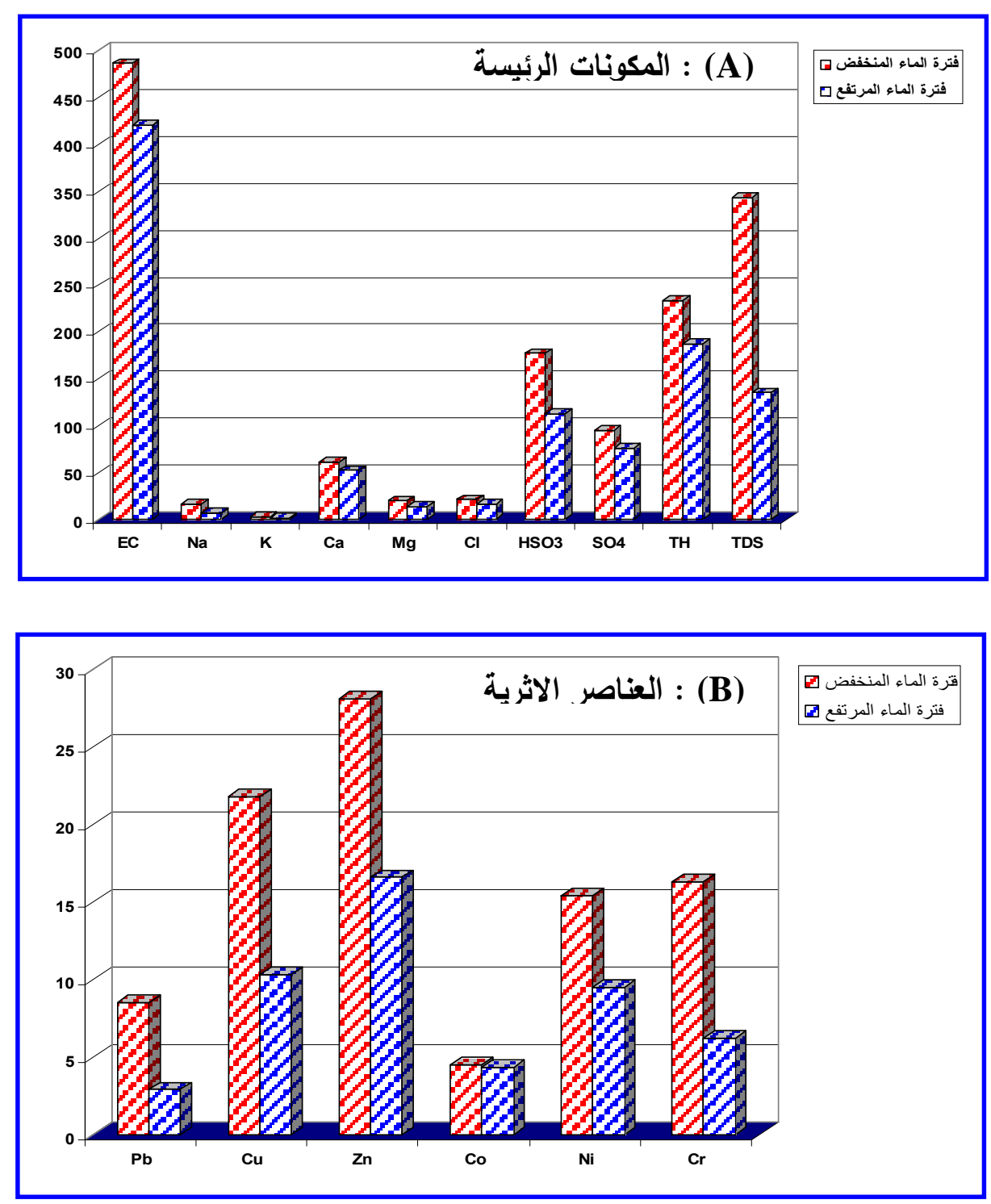

الثكل r: معدل تراكيز المكونات الرئيسة والعناصر الأثرية خلال فترتي تباين التصريف.

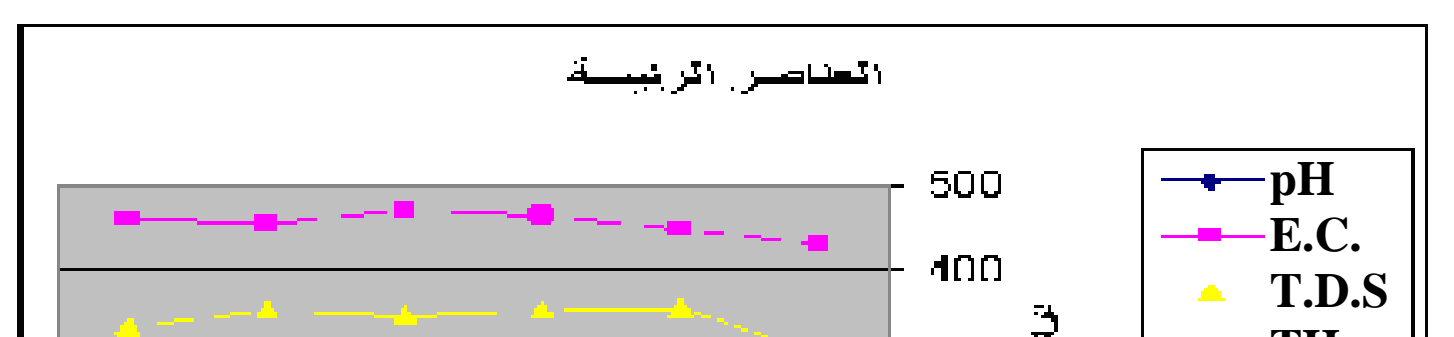




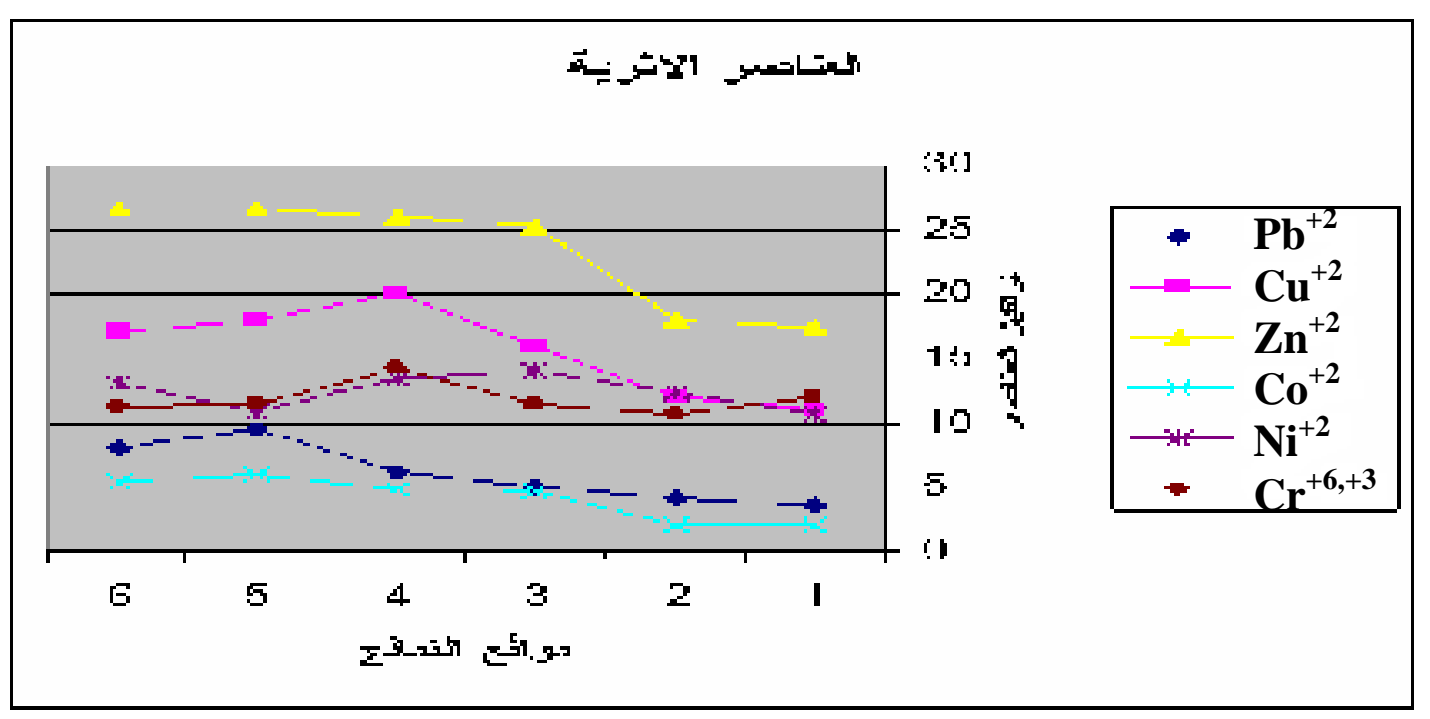

الشكل ع : تراكيز العناصر الرئيسة والعناصر الأثربة خلال مرور النهر بمدينة الموصل. 
الجدول 4 : جدول يمثل المواصفات القياسية لمياه الثرب حسب منظمة الصحة العالمية (WHO) لسنة 2003 والمواصفات الكندية لسنة 9199

\begin{tabular}{|c|c|c|c|}
\hline المكونات & WHO 2003 & مواصفات كندية & نهر دجلة (الدراسة الحالية) \\
\hline Turbidity NTU & $\bullet$ & $<5$ & - \\
\hline E.C $(\mu h o s / \mathrm{cm})$ & ספט & - & $\leq \leqslant 0.0$ \\
\hline pH Unit & $7.0-1.0$ & $7.0-1.0$ & V.r \\
\hline T.D.S & $1 \cdots$ & $<5000$ & rY\&. \\
\hline TH & - & - & $r 1 . . v$ \\
\hline $\mathrm{Ca}^{+2}$ & Vo & - & 07.1 \\
\hline $\mathrm{Mg}^{+2}$ & 125 & - & 17.8 \\
\hline $\mathrm{Cl}^{-}$ & 250 & $<250$ & $1 \Lambda . V$ \\
\hline $\mathrm{SO}_{4}^{-2}$ & ro. & $<500$ & 10.7 \\
\hline $\mathrm{Pb}^{+2}$ & 10 ppb & 10 ppb & 5.7 ppb \\
\hline $\mathrm{Cu}^{+2}$ & 2 ppm & 1 ppm & $16 \mathrm{ppb}$ \\
\hline $\mathbf{Z n}^{+2}$ & 3 ppm & 5 ppm & $22.3 \mathrm{ppb}$ \\
\hline $\mathrm{Ni}^{+2}$ & 20 ppb & - & $14.2 \mathrm{ppb}$ \\
\hline $\mathrm{Co}^{+2}$ & 50 ppb & - & $4.4 \mathrm{ppb}$ \\
\hline $\mathrm{Cr}^{+3,+6}$ & $50 \mathrm{ppb}$ & $50 \mathrm{ppb}$ & $11.2 \mathrm{ppb}$ \\
\hline
\end{tabular}

\section{الاستنتاجات}

ا - تكون المكونات الرئيسـة واغلب العناصـر الأثربـة (التي تم تحليلها) في مياه نهر دجلة ضمن الحدود الطبيعية والمقبولة عالمياً قبل دخول النهر المدينة. ץ- تزداد العسرة الكلية لمياه نهر دجلة خلال مرور النهر بمدينة الموصل. 
r- ارتفاع معظم تراكيز المكونات الرئيسة والعناصر الأثرية خلاد مرور النهر بمدينة الموصل ويتعدى قسم منها الموصفات العالمية.

ع - انخفاض تراكيز المكونات الرئيسة والعناصر الأثرية خلال فترة تصريف الماء المرتفع (فصل الثتاء) مقارنة بفترة الماء المنخفض (فصل الصيف) نتيجة ارتفاع تصريف النهر (عامل التخفيف والانتشار) نتيجة لسقوط مياه الأمطار او زيادة تصريف سد الموصل وقلة عمليات التبخير .

\section{المصادر العربية}

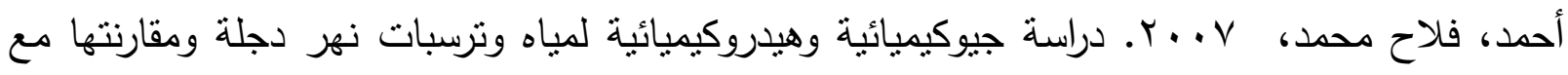

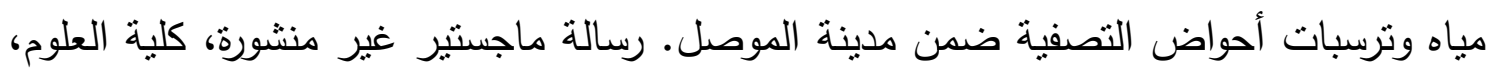

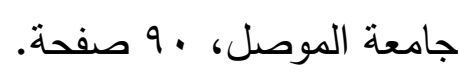

البياتي، هثام جاسم، •9191، هيدروكيميائية وجيوكيميائية نهر دجلة والتلوث المحتمل من القيارة إلى لى

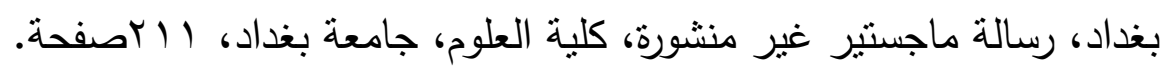

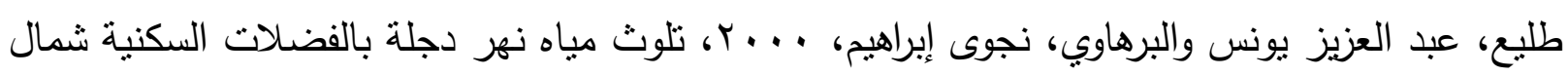

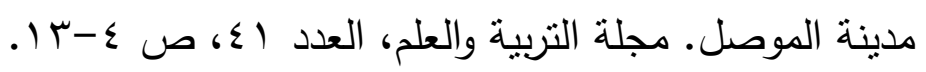

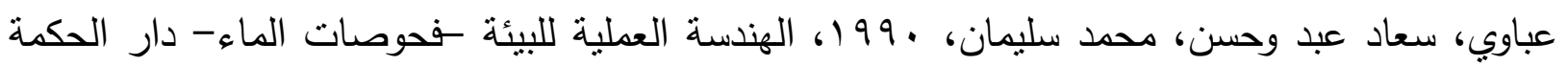

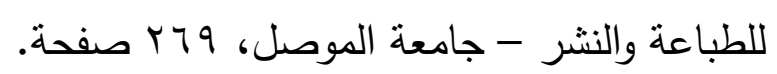
مديرية الموارد المائية، سجل معلومات تصاريف مياه نهر دجلة، ج ج . . r.

\section{المصادر الاجنبية}

Allent, S.E., Grimshw, H.W., Parkinson J.A. and Guarmby, C., 1973. Chemical Analysis of Ecological Materials. Blackwell. Scientific Publication, Oxford. England.

Al-Sawaf, F.D., 1977. Sulfate Reduction and Sulfur Deposition in the Lower Fars Formation, Northern Iraq. Economic Ecology Vol. 72, pp. 608-616.

APHA, 1998. Standard Method for the Examination of Water and Waste Water. $18^{\text {th }}$ ed. APHA, AWWA WDGE, United States of America.

Benoit, G. and Rozon, T.F., 1998. The Influence of Size Distruntion on the Practice Concentration Effect and Trace Metal Partitioning in Rivers Geochem. Cosmochim. Acta. Vol. 63, No. 1, pp. 113-127.

Baghdadi, A.I., 1973. Water Spring in Iraq, their Geological Characteristics and Utilization, Seminar on Ground Water, 10-15 March 1973, Foundation of Scientific Research and UNE SCO, Baghdad, Iraq. 14p.

Buday, 1980. The Regional Geology of Iraq, Unpublised. Repot, Sum. Library.

Drever, J.I., 1997. Geochemistry of Natural Waters. $3^{\text {rd }}$ ed., prentice-Hall Engle Wood Cliffs. 436p. 
Faust, S.D. and Aly, O.M., 1998. Chemistry of Water Treatment. $2^{\text {nd }}$ ed., Lewis publisher, 581p.

Fetter, C.W., 1980, Applied Hydrogeology. Bell and Howell Co., London, 488p.

Hem, J.D., 1985, Study and Interpretation of the Chemical Characteristic of Natural Water U.S.G.S Water supp. Paper, 2254, 263p.

Manahan, S.E., 2004, Environmental chemistry, CRC press, $8^{\text {th }}$ ed., Washington DC, USA.

Morris, R.D., Audet, A.M., Angelillo, I.F., Chalmers, T.C. and Mostell, F., 1992. Chlorination By-products and Cancer. Ameta- Analysis- American Jour. of Public Health, Vol. 82, No. 7, pp. pp.955-963.

Mustafa M.H. and Jankeer M.H., 2007. Quality Difference Between Tow Location on Tigris River Within Mosul City. Vol18, No1., pp. 111-124.

Picouet, C., Dupre, B., Orange, D. and Valladon, M., 2001. Major and Trace Elements Geochemistry of the upper Niger (Mail). Physical and Chemical Weathering Rates and $\mathrm{CO}_{2}$ Consumption. Chem. Geo. Vol. 181, pp. 93-124.

Sanders, L.L., 1998. A Manual of Filed Hydrogeology. Prentice-Hall, 381p.

Todd, D.K. and Mays, L., 2005. Ground Water Hydrology, ( ${ }^{\text {rd }}$ ed.) John Wiley and Sons, Inc, 636p.

UNISCO, 1983. Study of the Relationship Between Water Quality and Sediment Transport, Tech. paper in Hydrology. France, 231P.

WHO, 2003. Guide Lines for Drinking Water Quality. World Health Organization $\left(3^{\text {rd }}\right)$. Vol. 1., 623p.

Yilmaz, Q., Kahraman, V. and Eral, C., 2003. Solidification /Stabilization of Hazardous Waste Containing Metals and Organic Contaminates. Jour. Environmental Engineering, Vol. 129, pp. 366-376. 